Finisterra, XXXVII, 73, 2002, pp. 101-107

\title{
A OBRA GEOGRÁFICA DE MARIANO FEIO
}

\author{
SuZANne DaveaU 1
}

Mariano Feio (1914-2001) foi um geógrafo invulgar, tanto pelo percurso muito pessoal que seguiu desde a sua formação de base até à sua diversificada vida profissional, como pela originalidade e novidade dos variados assuntos que abordou, aprofundou e divulgou. Procurou sempre chegar ao conhecimento rigoroso dos temas que decidiu estudar, não apenas pelo grande prazer intelectual que lhe trazia a investigação, mas pelo desejo de colocar à disposição de todos os utilizadores os resultados alcançados.

Homem reservado e até solitário, foi no plano pessoal um grande e fiel amigo, e um cidadão consciente, preocupado em contribuir para o que considerava o desenvolvimento lógico e harmonioso da sociedade humana, finalidade altruísta que norteou implicitamente os seus tão diversos estudos.

É difícil resumir os aspectos duma vida científica muito rica e, aparentemente, tão diversificada. Parte dos elementos que a constituem encontram-se já apresentados no livro de homenagem que lhe foi dedicado em 1986; parece portanto inútil repeti-los aqui. Apenas se irão escolher algumas das orientações da sua vida científica e as obras principais que as testemunham, para tentar mostrar a importância do seu contributo para o desenvolvimento do conhecimento de Portugal e, num plano mais geral, para o progresso e a utilização eficaz da ciência geográfica.

\section{CONTRIBUTO PARA O CONGRESSO INTERNACIONAL DE GEOGRAFIA DE 1949}

Licenciado em Engenharia Civil no Instituto Superior Técnico de Lisboa em 1936, Mariano Feio foi estudar Geologia, Paleontologia e Geomorfologia na Alemanha, em Berlim e Munique. Voltou para Portugal em 1942, tendo, pouco depois, sofrido um grave acidente de viação na Serra do Algarve, que lhe deixou

\footnotetext{
1 Investigadora do Centro de Estudos Geográficos, Universidade de Lisboa. E-mail: s.daveau@mail.telepac.pt
} 
sequelas dolorosas, que se foram acentuando com a idade, limitando cada vez mais a sua capacidade de andar; nunca deixou, no entanto, de praticar assiduamente o trabalho de campo. Em 1943, descobriu o fenómeno dos terraços fluviais escalonados do Guadiana, na companhia de Amilcar Patrício, então professor do liceu de Beja, que tinha ajudado Orlando Ribeiro no estudo dos terraços do Mondego. Mariano Feio empreendeu o estudo geomorfológico do vale do Guadiana e foi convidado por Orlando Ribeiro para Assistente de Geografia na Universidade de Lisboa em 1944.

Começou assim a primeira fase, lisboeta, da sua vida profissional, em breve dominada pela organização do primeiro Congresso Internacional de Geografia do pós-guerra, aventura científica muito arriscada, em que as aspirações entusiastas de Orlando Ribeiro foram eficazmente apoiadas por um pequeno grupo de discípulos, colegas e amigos, entre os quais se destaca o «incomparável companheiro de trabalho» que Mariano Feio foi para Orlando Ribeiro. Além da sua contribuição na organização geral do encontro e na publicação dos quatro volumes de Actas (1950-52), sobressaem duas obras individuais, que testemunham já as notáveis qualidades que irão marcar toda a sua obra. Publicou, em 1948, a Bibliografia Geográfica de Portugal, com autoria generosamente atribuída a Hermann Lautensach, e a indicação, em letras miúdas, Adaptação e complementos de Mariano Feio. Com efeito, compilou, organizou e traduziu as várias resenhas bibliográficas já publicadas por Lautensach sobre Portugal, mas completou-as e reorganizou-as profundamente, oferecendo assim a todos os interessados um excelente instrumento de trabalho, que reúne o essencial da bibliografia geográfica sobre Portugal continental até 1946. Este livro, esgotado, foi reeditado em 1972, altura em que já estava em preparação, sob a direcção sucessiva de Ilídio do Amaral e de Suzanne Daveau, o segundo volume, referente ao período 1947-74, que se conseguiu publicar em 1982. A muito desejável continuação desta obra, instrumento de trabalho imprescindível para todos os que trabalham sobre Portugal, exige abnegação, generosidade, método e persistência, e faz parte da lista dos projectos do Centro de Estudos Geográficos de Lisboa, infelizmente até hoje não concluídos.

Outra obra notável da mesma época é o livro-guia duma das excursões do Congresso, Le Bas Alentejo et l'Algarve, publicado em 1949 e reeditado em 1983. Aplicando o esquema de organização concebido por Orlando Ribeiro para os seis livros da colecção, é uma apresentação equilibrada dos traços geográficos essenciais da região percorrida, durante sete dias, por uma das excursões do Congresso. Este pequeno e denso livro, um dos melhores da colecção, abundantemente ilustrado com mapas, fotografias e desenhos expressivos, mostra como Mariano Feio tinha já assimilado excelentemente o essencial da visão geográfica regional, onde se imbricam os traços naturais e a obra dos homens. Perdura, até hoje, como a melhor apresentação de conjunto da metade Sul de Portugal. 


\section{O GEOMORFÓLOGO}

Enquanto dedicava tantos esforços a trabalhos de interesse comum, Mariano Feio não descuidava a preparação da dissertação de doutoramento. Tendo começado o estudo do relevo do Sul de Portugal pelo problema da evolução do vale do Baixo Guadiana (1946), alargou progressivamente o âmbito do seu trabalho para tentar entender a evolução de conjunto da extremidade meridional de Portugal, até à latitude da Serra de Portel. O fio condutor foi «a peneplanície do baixo Alentejo, o elemento morfológico fundamental desta parte do país». Publicada em 1951, a tese foi defendida em Janeiro de 1952.

É uma obra ambiciosa, que conseguiu levar a cabo aplicando uma metodologia simples e rigorosa, bem adaptada aos muito parcos recursos documentais de que os primeiros geomorfólogos dispunham em Portugal. Basta lembrar que a maior parte da região que estudou não tinha ainda cobertura cartográfica de pormenor, nem topográfica, nem geológica. Apenas se podia praticar, portanto, uma espécie de reconhecimento prévio, de exploração dum espaço mal documentado. E, no entanto, a tese de Mariano Feio perdura, até hoje, como uma das obras-primas que fundaram a Geomorfologia portuguesa, constituindo a sua leitura uma insubstituível lição de exigência metodológica.

Durante os anos seguintes, Mariano Feio parece ter consagrado a maior parte dos seus esforços a temas bem diferentes. No entanto, a Geomorfologia continuou sempre a apaixoná-lo e a ser a base sólida e ampla da sua visão do mundo. As suas publicações testemunham esta continuidade. Sem esquecer os sempre incisivos artigos, que publicou sobre diversos aspectos do relevo do Noroeste de Portugal, de 1948 a 1951, relembram-se as suas investigações sobre o Nordeste brasileiro, onde ensinou durante dois anos (1953 e 1954, em Pernambuco), sobre a Índia portuguesa (percorrida em 1955-56) e, sobretudo, sobre Angola, onde realizou várias missões de estudo entre 1958 e 1966, acumulando vinte e três meses de trabalho de campo. Recordará com saudade estes «tempos que foram dos melhores da minha vida». Em consequência da tardia política de desenvolvimento imperial portuguesa, Mariano Feio teve ao seu dispor, em Angola, uma cobertura cartográfica bem melhor que no Alentejo: o excelente mapa topográfico na escala 1:100 000 e levantamentos geológicos e pedológicos, ainda incompletos mas de qualidade.

Os seus estudos angolanos estão reunidos numa espessa memória, O Relevo do Sudoeste de Angola (1981), que fornece os traços fundamentais duma região duas vezes mais vasta que Portugal. Descreve a grandiosa escadaria de aplanações, que culmina no planalto da Humpata, a mais de $2000 \mathrm{~m}$ de altitude; o contraste entre a vertente litoral escalonada e as vastas extensões endorréicas do interior; a evolução complexa do rio Cunene, recentemente desviado para o Atlântico. Um esquema de evolução geral é proposto e argumentado, mas cuidadosamente separado da exposição dos factos observados. Esta obra constitui, sem dúvida, um dos sólidos contributos científicos que os geógrafos portugueses 
deixaram a África, durante o período, infelizmente muito curto, em que encontraram condições propícias à realização das suas investigações.

Mariano Feio nunca deixou de reflectir sobre a Geomorfologia do Sul de Portugal. A partir de 1980, foi publicando uma série de artigos sobre as serras que acidentam o Alto Alentejo. Estes estudos, e outros sobre o clima do Alentejo, de que se falará a seguir, foram quase sempre realizados em colaboração com jovens investigadores da nova Universidade de Évora, onde passou a ser Professor Catedrático em 1975 e onde orientou e animou eficaz e apaixonadamente ensino e investigação. Em 1993, publicou na Finisterra, em colaboração com António Martins, um denso artigo de síntese sobre «O relevo do Alto Alentejo».

Sempre preocupado com a eficaz difusão dos conhecimentos científicos entre o vasto público não especializado, que precisa deles para conseguir uma actuação mais eficaz, Mariano Feio pediu-me ajuda, em 1998, para realizar e publicar uma síntese sobre $O$ Relevo de Portugal. Mais de meio século tinha sido necessário para reunir conhecimentos suficientes sobre o relevo das várias regiões portuguesas, dado o pequeno número de investigadores que se dedicaram, no país, a este ramo científico difícil. Com a conclusão da tese de António Martins sobre a evolução do relevo da Bacia sedimentar do Baixo Tejo, tornou-se finalmente possível realizar o esforço de simplificação e ordenação, exigido pela eficaz divulgação destes conhecimentos. Não foi, infelizmente, possível acabar esta obra de síntese a tempo do seu promotor a ver publicada. Mas este livro em preparação será a melhor homenagem que os seus colegas lhe poderão prestar.

\section{A PRÁTICA EXPERIMENTAL DA AGRICULTURA}

Tendo herdado uma vasta exploração agrícola, situada nos solos pobres da bacia sedimentar do Sado - a Herdade do Outeiro (1200 ha), em Canhestros -, Mariano Feio decidiu fazer dela um laboratório de experimentação, para tentar definir racionalmente as técnicas agrícolas mais bem adaptadas ao ambiente natural do Sul de Portugal e às condições socio-económicas vigentes. Esta autêntica aventura, que iniciou no começo dos anos 50 e que prolongou quase continuamente até à morte, em condições muito diversas e, às vezes, muito difíceis, em função dos sobressaltos políticos e económicos, sofridos tanto no plano nacional como europeu, está em grande parte relatada, à excepção dos anos mais recentes, nos densos artigos que Olivier Balabanian e Joaquim Sampaio lhe dedicaram no livro de homenagem de 1986. O próprio Mariano Feio teve sempre o cuidado de divulgar os resultados práticos que ia obtendo, em sucessivos artigos, regularmente publicados nas revistas regionais e da especialidade, e também através do seu ensino, em Évora e Beja, a partir de 1975.

Mas, além disso, reuniu as suas principais conclusões em quatro livros, que se apresentam a seguir. Dois deles tratam de temas relativos ao clima nas suas relações com a agricultura, enquanto dois outros apresentam a evolução 
histórica da agricultura praticada no Alentejo e as possíveis vias da sua futura adaptação e reconversão. Em todos estes livros, nota-se o mesmo rigor exigente da análise, a simplicidade metódica da exposição, que se quer acessível a todos, e a preocupação pragmática em sugerir somente soluções economicamente viáveis.

O primeiro livro, publicado em 1986, em colaboração com Virgínia Henriques, analisa cartograficamente a intensidade e distribuição regional das «secas» ocorridas em Portugal em dois anos recentes (1980-81 e 1982-83), comparadas com secas anteriores. Apresentam-se igualmente os prejuízos causados por estas secas na produção agrícola, de sequeiro e de regadio, na energia eléctrica e no abastecimento de água às populações. Trata-se portanto de um trabalho descritivo, com caracterização numérica tão precisa quanto possível, dum fenómeno natural de grande importância para a agricultura, mas sem que os autores se tenham embrenhado na sempre especulativa procura das causas dos fenómenos, nem, muito menos, na previsão de qualquer sonhada evolução do clima. Simplicidade austera, rigor crítico das fontes, este pequeno livro reflecte bem a maneira de trabalhar do seu principal autor.

De âmbito muito mais vasto, mas de metodologia parecida, é o livro publicado em 1991, Clima e Agricultura. O subtítulo apresenta o seu conteúdo e finalidade: "Exigências climáticas das principais culturas e potencialidades agrícolas do nosso clima». De apresentação simples e clara, o livro reúne comodamente uma preciosa informação, resultante da vasta experiência do autor, ganha nos locais onde investigou (Portugal, Brasil, Goa, Angola) e onde realizou longas visitas de estudo (Israel, Marrocos, Itália, África do Sul, Califórnia e Espanha). As primeiras linhas da Introdução são esclarecedoras: "O objectivo do presente trabalho é ao mesmo tempo didáctico e de divulgação: apresentar as exigências de clima das principais culturas, tendo em vista a adaptação às nossas condições naturais (...). Mas nem só as condições naturais contam: é preciso que haja consumo, o que toma expressão num mercado e num preço (...). Para o agricultor, o preço tem a maior importância (...)». O pragmatismo da investigação praticada por Mariano Feio, a sua preocupação constante em fornecer a todos instrumentos de trabalho precisos e eficazes estão, portanto, uma vez mais, patentes neste livro.

Dois outros livros são dedicados à prática da agricultura em Portugal, confrontada com as novas condições resultantes da integração europeia. O primeiro, A Reconversão da Agricultura e a Problemática do Eucalipto, publicado em 1989, discute as alternativas possíveis à provável necessidade de abandonar os cereais, "cultura tradicional e principal opção dos países de clima mediterrânico, quanto às culturas de grande superfície», sendo as alternativas «escassas, pobres e difíceis, quando não fantasistas». Reconhece que é «um fundo de quixotismo sem remédio que [o] leva a julgar que se presta serviço quando se toma posição contra o que se considera muito errado, neste caso as afirmações sem fundamento que se têm feito contra o eucalipto", árvore então alvo das mais graves e generalizadas acusações, que não passavam, segundo ele, de afir- 
mações repetidas sem fundamento. Ora, «afirmar sem fundamento é não só a negação do espírito científico, mas a negação do pensamento racional e objectivo, principal base do progresso». Como de costume, a argumentação é apresentada metodicamente, baseada na análise de casos concretos, clara e sucintamente transmitidos.

O último livro de Maria Feio, publicado em 1998, apresenta, em duas partes, A Evolução da Agricultura do Alentejo Meridional. Mostra primeiro, comparativamente, a utilização do solo em fins do século XIX e meados do século XX, graças a dois conjuntos documentais de grande valor, as Cartas Agrícolas e Memórias Estatísticas de Gerardo Pery e a Carta Agrícola e Florestal do SROA, que lhe permitiram calcular a evolução em superfície dos principais tipos de utilização do solo, para cada concelho, e a evolução em superfície, produção e rendimento das principais culturas. Para o período mais recente, faltava uma base documental de valor comparável, o que obrigou Mariano Feio a basear fundamentalmente a sua análise nos preços, despesas, remuneraçóes e subsídios. A sua conclusão é algo pessimista e demonstra, sobretudo, a dependência completa das opções possíveis de qualquer tipo de agricultura comercial tanto, como foi sempre o caso, dos dados locais naturais, solos e clima, como dos factores económicos, que actuam cada vez mais, já não à escala regional ou nacional, mas à escala europeia ou mundial.

Tentou-se, através das curtas resenhas apresentadas acima, dar ideia das características principais da obra científica de Mariano Feio. Falta ainda, no entanto, uma faceta a esta apresentação, faceta secundária é verdade, mas muito significativa: o interesse que este geógrafo prestou sempre à organização e às crenças das sociedades com que conviveu. Citam-se apenas as duas publicações mais importantes: o livro sobre As Castas Hindus de Goa, resultante da sua viagem à Índia em 1955-56, e o artigo sobre «Um possesso numa aldeia do Alentejo nos anos 80 », penetrante análise da mentalidade mágica que perdura enraizada nas sociedades actuais.

\section{Obras de Mariano Feio apresentadas:}

1948 - Bibliografia Geográfica de Portugal. Adaptação e complementos de uma obra de H. Lautensach. Centro de Estudos Geográficos, Lisboa.

1949 - Le Bas Alentejo et l'Algarve (Livret-Guide de l'Excursion E). XVI Congrès International de Géographie, CEG, Lisboa.

1951 - A Evolução do Relevo do Baixo Alentejo e Algarve. Comunicações dos Serviços Geológicos de Portugal, 32, Lisboa.

1979 - As Castas Hindus de Goa. Estudos de Antropologia Cultural, 11, Junta de Investigações do Ultramar, Lisboa. 
1981 - O Relevo do Sudoeste de Angola. Estudo de Geomorfologia. Memória da Junta de Investigações Científicas do Ultramar, 2. ${ }^{a}$ série, 67, Lisboa.

1985 - «Um possesso numa aldeia do Alentejo nos anos 80», Revista Lusitana, 6, Lisboa (em colaboração com M. Teixeira).

1986 - As Secas de 1980-81 e de 1982-83 e as Principais Secas Anteriores. Intensidade e Distribuição Regional. Memórias do Centro de Estudos Geográficos, 10, Lisboa (em colaboração com Virgínia Henriques).

1989 - A Reconversão da Agricultura e a Problemática do Eucalipto. Associação Central de Agricultura Portuguesa, Lisboa.

1991 - Clima e Agricultura. Exigências Climáticas das Principais Culturas e Potencialidades Agrícolas do Nosso Clima. Ministério da Agricultura, Pescas e Alimentação, Lisboa.

1993 - O relevo do Alto Alentejo, Finisterra - Revista Portuguesa de Geografia, XXVIII (55-56), Lisboa (em colaboração com António Martins).

1998 - A Evolução da Agricultura do Alentejo meridional. As cartas Agrícolas de G. Pery. As Difíceis Perspectivas Actuais na Comunidade Europeia. Edições Colibri, Lisboa.

\section{Sobre Mariano Feio:}

BRITo, R. Soeiro (coord.) (1986) - Estudos em Homenagem a Mariano Feio, Lisboa.

BRITo, R. Soeiro (2001) - “In Memoriam”. GeoInova,4, Lisboa: 5-6.

Carvalho, G. Soares; Henriques, Virgínia (2001)-Mariano Feio e o Quaternário, Estudos do Quaternário, 4, Lisboa: 3-5

Daveau, Suzanne (2001) - Mariano Feio, geógrafo e amigo, Ler História, 40, Lisboa: 186-188.

Roxo, Maria José (2001) - Uma pessoa cativante, Ler História, 40, Lisboa: 189-190. 